THURSDAY, FEBRUARY I2, 1903.

\section{THE SCIENTIFIC WORK OF SIR GEORGE STOKES.}

TOKES ranged over the whole domain of natural $D$ philosophy in his work and thought ; just one field -electricity-he looked upon from outside, scarcely entering it. Hydrodynamics, elasticity of solids and fluids, wave-motion in elastic solids and fluids, were all exhaustively treated by his powerful and unerring mathematics.

Even pure mathematics of a highly transcendental kind has been enriched by his penetrating genius; witness his paper "On the Numerical Calculation of a Class of Definite Integrals and Infinite Series," ${ }^{1}$ called forth by Airy's adnirable paper on the intensity of light in the neighbourhood of a caustic, practically the theory of the rainbow. Prof. Miller had succeeded in observing thirty out of an endless series of dark bands in a series of spurious rainbows for the determination of which Airy had given a transcendental equation, and had calculated, of necessity most laboriously, by aid of ten-figure logarithms, results giving only two of those black bands. Stokes, by mathematical supersubtlety, transformed Airy's integral into a form by which the light at any point of any of those thirty bands, and any desired greater number of them, could be calculated with but little labour and with greater and greater ease for the more and more distant places where Airy's direct formula became more and more impracticably laborious. He actually calculated fifty of the roots, giving the positions of twenty black bands beyond the thirty seen by Miller.

With Stokes, mathematics was the servant and assistant, not the master. His guiding star in science, was natural philosophy. Sound, light, radiant heat, chemistry, were his fields of labour, which he cultivated by studying properties of matter, with the aid of experimental and mathematical investigation.

His earliest published papers [Cambridge Philosophical Society, April 25, 18+2, and M ty 29, 1843, followed (November 3,1846 ) by a Supplement] were on fluid motion; the second of these and its supplement contained a beautiful mathematical solution of the problem of find. ing the motion of an incompressible fluid in the interior of a rectangular box to which is given any motion whatever, starting from rest with the contained liquid at rest. This solution, as shown in Thornson and Tait's "Natural Philosophy," $\$ \S 704$ and 707 , is also applicable to the very practical problem of finding the torsional rigidity of a rectangular bar of metal or glass. For every oblong rectangular section, the solution may be put in one or other of two interestingly different forms, which are identical when the cross-section is square and are always both convergent. One of them converges much more rapidly than the other when one of the diameters of cross-section is more than two or three times the other. Regarding these two solutions, Thomson and Tait ( $\$ 707)$ say :-

1 "Collected Mathematical and Physical Papers," vol. i., pp. 329-357. From Cambridge Philosophical Society, March I1, 1850.

$$
\text { NO. } 1737 \text {, VOL. 67] }
$$

"The comparison of the results gives astonishing theorems of pure mathematics, such as rarely fall to the lot of those mathematicians who confine themselves to pure analysis or geometry, instead of allowing themselves to be led into the rich and beautiful fields of mathematical truth which lie in the way of physical research."

The 1843 paper contained his theory of the viscosity of fluids; and his definite mathematical equations for its influence in fluid motion, which constitute the complete foundation of the hydrokinetics of the present day. In the same paper, by reference to known facts, relating to natural and artificial solids, glass, iron, indiarubber, jelly, and results of experimental investigations, he relieved the theory of elastic solids from what. is now known as the Navier-Poisson doctrine of a constant proportion between the moduluses of resistance to compression and of rigidity (resistance to change of shape); and, following Green, gave us the equations of equilibrium and motion of isotropic elastic solids, with their two distinct moduluses, which constitute the whole theory of equilibrium and motion of elastic solids as we have it at this day.

Seven years later, building on the foundation he had laid, he communicated another great paper to the Cambridge Philosophical Society, ${ }^{1 . " O n}$ the Effect of the Internal Friction of Fluids on the Motion of Pendulums." In this paper he solved the following very difficult problems, taxing severely the mathematical power of anyone trying to attack them.

(1) The oscillations of a rigid globe in a mass of viscous fluid contained in a spherical envelope having for its centre the mean position of the globe.

(2) The oscillations of an infinite circular cylinder in an unlimited mass of viscous fluid.

(3) Determination of the motion of a viscous fluid about a globe moving uniformly with small velocity through it.

(4) The effect of fluid friction in causing the rapid subsidence of ripples in a puddle and the slow subsidence from day to day of ocean waves when the storm which produced them is followed by a calm.

Of solution (3) he makes a most interesting applic. ation to explain the suspension of clouds by determining from the known viscosity of air, the terminal velocity of an exceedingly minute rigid globule of water falling through air. His formula for this has been used with excellent effect in the Cavendish Laboratory by Prof. J. J. Thomson and his research corps; first, I believe, by Townsend in determining approximately the diameter of the globules in a mist produced hy electrolysis, by observing its rate of subsidence when left to itself in a glass bell.

In the interval between the two great papers of 1843 and 1850 , Stokes gave another magnificent hydrokinetic paper," "Theory of Oscillatory Waves," containing a thoroughly original and masterly investigation of a most difficult problem, the determination of the motion of steep deep-sea waves. As an illustration of his results, he gives a diagram (M. and P.P., vol. ii., p. 212) showing the shape of a deep-sea wave in which the difference of level between crest and hollow is seven-fortieths of the

I December 9, 1850, M. and P. P., vol. ii., pp. 1-144.

2 Camb. Phil. Soc., March, 1847 , M. and P. P., vol. i., pp. $197-229$ with supplement first published in the reprint $M$. and P. P., pp. $316-326$. 
wave-length-an admirable triumph of mathematical power.

He proved (vol. i. p. 227) that the steepest possible wave has a crest of $120^{\circ}$, with slope of $30^{\circ}$ down from it before and behind. $\mathrm{He}$ hoped to work out fully its shape, and would no doubt have succeeded had time permitted.

Four short papers of July, I 845, February, I 846 , May, 1846 , and July, $1846,{ }^{1}$ show that in those early times Stokes had taken to heart the wave theory of light. His later splendid work on light has given such great results that even in the scientific world Stokes is often thought of only as a worker in optics and the wave theory of light. Truly his work in this province is more than enough for the whole life-time of a hard-working searcher in science.

A short paper of great value," "On the Formation of the Central Spot of Newton's Rays beyond the Critical Angle," touches in its title a physical question of fundamental importance-What motion takes place in the ether close behind the perfect mirror presented by total internal reflection? And the answer to it given in the paper is admirably clear and satisfactory.

A little later, we find one of the most important of all of Stokes's papers on light, ${ }^{3}$ "The Dynamical Theory of Diffraction." This paper contains the full mathematical theory of the propagation of motion in a homogeneous elastic medium. It contains, also, application of the theory to the disturbance produced in ether by a Fraunhofer grating for the two cases of incident light, (1) with its vibrations in the plane of incidence, and (2) with its vibrations perpendiculur to that plane (therefore parallel to the lines of the grating). Lastly, it contains a description of an elaborate experimental investigation by himself, and a comparison of the results with theory, from which he concluded that the plane of polarisation is the plane perpendicular to the direction of vibrations in plane polarised light. This conclusion, not withstanding adverse criticism by Holtzmann, ${ }^{4}$ was confirmed by Lorenz, of Copenhagen. ${ }^{6}$ The same conclusion was arrived at from the dynamics of the blue sky by Stokes and Rayleigh, and from the dynamics of reflection at the surface of a transparent substance by Lorenz and Rayleigh. We may now consider it one of the surest truths of physical science.

The greatest and most important of all the optical papers of Stokes was communicated to the Royal Society on May 27, 1852, under the title " On the Change of the Refrangibility of Light." ${ }_{6}$ In this paper, his now wellknown discovery of fluorescence is described; according to which a fluorescent substance emits in all directions from the course through it, of a beam of homogeneous ligbt. The periods of analysed constituents of this fluorescent light, in all Stokes's experiments, were found to be longer than the period of the exciting incident light. But I believe fluorescent light of shorter periods than the exciting light has been discovered in later times.

Stokes found that the fluorescence vanished very

1 M. and P. P., vol. i., pp. 141-157.

2 Camb. Phil. Soc., December 11,1848 , M. and P. P., pp. 56-8x

3 Camb. Phil. Soc., November 26, 1849, M. and P.P., pp. $243-328$.

4.Poggendorff's Axnalen, vol. xcix., 1856, or Phil. Mag., vol. xiti. p. 135

SPoggendorf's A nnalen, vol. iii., 186o, or Phil. Mag., vol. xxi. p. $32 \mathrm{r}$.

6 Phil. Trans. and M. and P.P., pp. 259-407.

No. 1737 , voL. 67$]$ quickly after cessation of the incident light. A beautiful supplement to his investigation was made by Edmond Becquerel showing a persistence of the fluorescent light for short times, to be measured in thousandths of a second, after the cessation of the exciting light.

Stokes's fundamental discovery of fluorescence is manifestly of the deepest significance in respect to the dyna. mics of waves, and of intermolecular vibrations of ether excited by waves, and causing fresh trains of waves to travel through the fluorescent substance. The prismatic analysis of the fluorescent light for any given period of incident light was investigated by Stokes for a large number of substances in his first great paper on the subject, and was followed up by further investigations by Stokes himself in later years, of which some of the results are given in his paper "On the Long Spectrum of the Electric Light" (Phil. Irans., June I9, I862).

Stokes's great paper on the refrangibility of light is the last paper of the last volume (vol. iii.) hitherto published of his mathematical and physical papers. It is to be hoped that with the least posible delay we shall have a complete collected republication of all his other papers. Every one of them, however small, will in all probability be found to be a valuable contribution to science ; witness, for example, his paper of twenty-one lines in the Phil. Mag. for October, 1872 . Let us hope that manuscript may be found for the communication to the Royal Society promised at the end of that paper.

Stokes's scientific work and scientific thought is but partially represented by his published writings. He gave generously and freely of his treasures to all who were fortunate enough to have opportunity of receiving from him. His teaching me the principles of solar and stellar chemistry when we were walking about among the colleges some time prior to 1852 (when I vacated my Peterhouse fellowship to be no more in Cambridge for many years) is but one example. Many authors of communications to the Royal Society during the thirty years of his secretaryship remember, I am sure gratefully, the helpful and inspiring influence of his conversations with them. I wish some of the students who have followed his Lucasian lectures could publish to the world his Opticae Lectiones; it would be a fitting sequel to the "Opticre Lectiones" of his predecessor in the Lucasian chair, Newton.

The world is poorer through his death, and we who knew him feel the sorrow of bereavement. KELVIN.

\section{RECENT METHOD IN PRACTICAL $M A T H E M A T I C S$}

Höhere Analysis für Ingenieure. Von Dr. John Perry. Autorisierte deutsche Bearbeitung von Dr. Robert Fricke und Fritz Süchting. Pp. viii +423. (Leipzig und Berlin: Teubner, 1902).

CONSIDERING the poor opinion the Germans express for the school of mathematics in this country, it is a great honour for Prof. Perry that his "Calculus for Engineers" should be considered suitable for translation as conveying a message of new method worthy of imitation and adoption.

The improvement of the mathematical instruction 